University of Washington Tacoma

UW Tacoma Digital Commons

$9-24-2018$

\title{
Examining Men's Perceptions of GBV Prevention Programming Content
}

\author{
C.T. Allen \\ J. Carlson \\ E.A. Casey \\ University of Washington Tacoma, ercasey@uw.edu \\ R.M. Tolman \\ C. Leek
}

Follow this and additional works at: https://digitalcommons.tacoma.uw.edu/socialwork_pub

\section{Recommended Citation}

Allen, C.T.; Carlson, J.; Casey, E.A.; Tolman, R.M.; and Leek, C., "Examining Men's Perceptions of GBV Prevention Programming Content" (2018). Social Work \& Criminal Justice Publications. 527.

https://digitalcommons.tacoma.uw.edu/socialwork_pub/527

This Article is brought to you for free and open access by the Social Work \& Criminal Justice at UW Tacoma Digital Commons. It has been accepted for inclusion in Social Work \& Criminal Justice Publications by an authorized administrator of UW Tacoma Digital Commons. 


\section{EXAMINING MEN'S PERCEPTIONS OF GENDER-BASED VIOLENCE PREVENTION PROGRAMMING CONTENT}

Christopher T. Allen; University of Massachusetts Lowell; christopher_allen@uml.edu University of Massachusetts Lowell 113 Wilder Street, Suite 300, Lowell, MA 01854-3059 Cell Phone: (803) 917-4761 Fax: (612) 486-7767

Juliana Carlson; University of Kansas, School of Social Welfare; jmcarlson@ @u.edu Erin A. Casey; University of Washington, Tacoma; ercasey@uw.edu

Richard M. Tolman; University of Michigan, School of Social Work; rtolman@umich.edu Cliff Leek; University of Northern Colorado; cliff.leek@unco.edu

\section{$\underline{\text { Author Note }}$}

The authors wish to acknowledge the many people who supported this research. We thank Juan Carlos Areán, Rus Funk, Jonathan Grove, and Oswaldo Montoya each of whom generously donated consultation supporting the content and translation of the survey used in this research. We also wish to express our gratitude to our survey participants and to the Mobilizing Men for Violence Prevention Global Advisory Board. Finally, thank you to the anonymous reviewers. $\underline{\text { Key Words }}$

gender-based violence; prevention; men 


\begin{abstract}
As global efforts to engage men in preventing gender-based violence (GBV) continue to grow, understanding male participants' perceptions of prevention events is needed. Data from a global sample of 319 men who had attended GBV prevention events were used to: (1) assess men's perceptions of what topics were covered, (2) determine whether profiles of these perceptions could be identified, and (3) describe the degree to which content prerception profiles are associated with levels of men's motivation and confidence related to anti-violence action. Latent class analysis identified four perception profiles of prevention topics. Implications for GBV prevention programming are discussed.
\end{abstract}


Anti-violence organizations across the globe increasingly see men's commitment to and action in prevention efforts as necessary to end violence against women and girls (Flood, 2005). This growing consensus has resulted in a dramatic surge in men's commitment to preventing violence and is reflected in an exponential growth of global efforts to engage men as antiviolence allies (Kimball, Edleson, Tolman, Neugut, \& Carlson, 2013). This curent zeitgiest emphasizing men's engagement in prevention has resulted in diverse programming content. Recently, Storer and colleagues (2016) found that, globally, organizations' prevention work often reflects locally specific ways of conceptualizing prevention, and a variety of combinations of strategies (e.g., policy building, community mobilization) that do not strictly conform to the predominant Western, public health conceptualizations of primary, secondary, and tertiary prevention. Such findings are important because they underscore the significance of contextually relevant programming that is tailored to norms of the community. For example, even if critiques of gender and masculinity are commonplace in prevention programs, the content and methods used must vary by audience to be effective (Peacock \& Barker, 2014). Additionally, they stress that comprehensive GBV prevention programming utilizes complimentary components to influence relevant attitudes and behaviors rather than simply a collection of information and activities (Nation, et al., 2003).

Rather, comprehensive programming must influence the development and maintenance of the behaviors which contribute to ending GBV. This means teaching men and boys skills for confronting misogyny, challenging behaviors and systems which permit the objectification and exploitation of women and girls, and expressing masculinity in non-violent ways. The Theory of Planned Behavior (Fishbein et al., 2001) posits that such behavior change requires that: (1) the individual has positive intention to perform the behavior(s), (2) the individual has the skills 
needed to perform the behavior(s), and (3) there are no environmental constraints against performing the behavior(s). However, even developing positive intentions toward GBV prevention among men and boys is a challenge. As noted by Berkowitz (2004, para. 18), men and boys "who work to end violence against women are challenging the dominant culture and the understandings of masculinity that maintain it." To overcome such a formidable environmental constraint, some behavior change resesearch (e.g., Fishbein et al., 2001) suggests that using varied teaching, presentation, and engagement strategies have the greatest likelihood of success.

As research on the characteristics of effective prevention programming supports the range of prevention programming approaches documented by the World Health Organization (2007; 2010) and more recently by Storer and associates (2016), it is imperative for the field to examine and understand if these efforts are impacting men's willingness and motivation to participate in ending GBV. This exploratory study builds upon existing literature by addressing the following research aims: (1) to assess men's perceptions of what topics were covered in GBV prevention events ${ }^{1}$ in an international sample; (2) to determine determine whether profiles of these perceptions could be identified; and (3) to describe the degree to which content perception profiles are associated with regionality, comprehensiveness, levels of men's motivation, and confidence related to anti-violence action.

\section{METHOD}

\section{$\underline{\text { Procedures }}$}

Data for these analyses come from a larger project examining the perceptions, beliefs, and behavior of men who are involved in violence prevention around the world, as well as those men's experiences with violence prevention events and work. Participants completed an online, 
anonymous survey available in English, Spanish, and French. Recruitment of participants occurred via email and postings on several violence and prevention-related email list-serves. Emails advertising the project were also sent to violence prevention and intervention programs globally, located through web-based searches targeting every region of the world. The research team also did an extensive, web-based global search for organizations involved in violence prevention. Organizations whose contact information was publicly accessible, were sent invitation emails (in English, Spanish and French) two times each, detailing the survey, inviting participation, and requesting that the invitation be forwarded to other potential participants. A small number of participants (19) were recruited through two organizations that used the survey to evaluate their own prevention events; these specific events occurred in the USA and Sweden. Eligible participants included those who: were male-identified, over 18 years of age, and who had attended any GBV event in the past year. The Institutional Review Board at a public university approved all procedures.

\section{$\underline{\text { Participants }}$}

Of the 471 people who answered the screening questions, 407 eligible participants responded to the survey. Eighty-eight participants indicated their most recently attended event was aimed at men who had previously used violence in relationships. Because the goal of this paper was to describe primary prevention events (as opposed to violence intervention programming), these participants were removed from analyses described here. The remaining 319 participants represented regions from around the world. Sample characteristics are detailed in Table 1, below. The majority of survey participants were from North America (55.8\%). The largest age group in the sample was 31-40-year olds, comprising $26 \%$ of the sample. Though many participants stated that English was their primary written and spoken language $(68.3 \%$ and 
$65.2 \%$, respectively), Spanish was the primary written and spoken language for nearly $20 \%$ percent of participants. Slightly more than half of participants $(54.2 \%)$ reported that they volunteer at an organization that includes violence prevention as part of its mission. Twenty-nine and a half percent identified as a staff member or volunteer at an organization that provided treatment for violent men. Forty-seven percent of the sample reported having worked in preventing violence against women for between zero and five years. Of the participants, 50.2\% reported spending between zero and five hours a week helping to end violence against women $(M=13.11 ; S D=15.24)$.

Approximately $91 \%$ of participants reported the date of their most recently attended violence prevention event. The reported violence prevention event occurred as far back as the second quarter (i.e., between April and June) of 2011 and as recently the first quarter of (i.e., between January and March) of 2014. The majority of responding participants attended their most recent violence prevention event in either $2013(67.2 \%)$ or $2014(27.2 \%)$.

Table 1 about here

\section{$\underline{\text { Measures }}$}

\section{Topics Covered at Violence Prevention Events}

Participants were asked to identify all topics discussed at their most recently attended violence prevention event. Seventeen possible topics were generated by the authors based on previous qualitative work by the research team and consultation with practitioners in the field and presented for selection (blinded for review). Additionally, participants could also select an 
"other" option if the event covered a topic not reflected in the list. Topic items are provided in Table 3.

Impact of Events/Attitudes and Behavioral Intentions Toward Anti-Violence Work The impact of attending a violence prevention event was assessed using 12 items informed by previous work (blinded for review) and revised by a committee of violence prevention researchers and activists. Response options spanned a seven-point scale with the following anchor points: 1="strongly disagree," 4="neither agree nor disagree," and 7 ="strongly agree.” Eight items specifically asking about how attendance at the event affected their motivation for involvement in violence prevention work were averaged to create a summary variable, called motivation. A representative item from this set is: "Because of this event I am motivated to talk to other men about this issue." The alpha coefficient for these items was excellent $(\alpha=.95)$. Four items specifically asking about how attendance at the event affected their confidence for being involved in violence prevention work were averaged to create a summary variable, called confidence. A representative item from this set is: "Because of this event I am more confident that I have something positive to contribute to ending violence against women." The alpha coefficient for these items was excellent $(\alpha=.93)$.

\section{Methods of Content Delivery}

Ten methods of content delivery were generated by the authors and presented for selection. These included options such as, "someone led a discussion," and "people who were affected by violence shared their stories." (See Table 3 for full list of content delivery items). Additionally, participants could also select an "other" option if the event delivered content using a method not reflected in the list. Responses to these items were summed to determine the total number of different content delivery methods used the most recently attended event. 


\section{Event Region}

As some regions were underrepresented in the sample, a binary variable was created to reflect whether participants attended an event in North America (a region which was overrepresented) or elsewhere.

\section{Involvement in Organizing Event}

Participants were asked to provide a "yes/no" response to the following question, "Were you involved in organizing this [the most recently attended] event?"

\section{$\underline{\text { Data Analysis }}$}

To address the first research aim, “to assess men's perceptions of what topics were covered in GBV prevention events in an international sample," we examined the percentage of men endorsing each of the possible 17 violence prevention related topics or who indicated that some "other" topic was covered.

To address the second research aim, "to determine determine whether profiles of these perceptions could be identified," we used latent class analysis (LCA) to identify prevention programming content by topic. LCA allows for the identification of homogeneous subgroups (i.e., "classes") within larger samples without imposing a priori assumptions about the nature of those subgroups (Lanza \& Collins, 2008). Analyses were conducted using Mplus version 7.4 (Muthén \& Muthén, Mplus User's Guide. Seventh Edition., 1998-2015). As there are currently no agreed upon criteria for determining the number of classes, models were estimated iteratively with an increasing number of classes specified at each step and model fit was assessed by comparing the values of the following metric across models (Nylund, Asparouhov, \& Muthén, 2007): the Bayesian Information Criterion (BIC; Schwartz, 1978), Akaike’s Information Criterion (AIC; Akaike, 1987), entropy (Ramaswamy, Desarbo, Reibstein, \& Robinson, 1993), 
the Lo-Mendell-Rubin (LMR; Lo, Mendell, \& Rubin, 2001) likelihood difference test, and the Parametric Bootstrap Likelihood Ration Test (BLR; McLachlan \& Peel, 2000). For both the BIC and AIC, the lower values indicate better fitting models (Nylund, Asparouhov, \& Muthén, 2007). For entropy, values above .80 are indicative of models with well-defined classes (Ramaswamy, Desarbo, Reibstein, \& Robinson, 1993). For both the LMR and BLR, a $p$ value of less than or equal to .05 indicates that the $k-1$ model is rejected in favor of the model with $k$ class model (Nylund, Asparouhov, \& Muthén, 2007). When considering models, we prioritized model parsimony and aimed to identify the model with smallest number of meaningful classes. After the model is fitted, the probability of a respondent belonging to each of the latent subgroups is calculated. The subgroup with the greatest probability is assigned to each respondent. Though not used as a criterion for assessing model fit, we also examined the percentage of respondents correctly classified as evidence of the robustness of the final model. The following variables were included in the best fitting LCA model as distal outcomes to determine their relations men's perceptions of programming content: event region, involvement in organizing, and methods of content delivery.

To address the third research aim, "To describe the degree to which content prerception profiles are associated with regionality, comprehensiveness, levels of men's motivation, and confidence related to anti-violence action," we modeled the best fitting LCA model with distal outcomes to assess the relations between class membership and observed variables (Lanza, Tan, \& Bray, 2013) of interest related to anti-violence work: bystander attitudes and self-efficacy.

\section{RESULTS}

\section{$\underline{\text { Topics Covered at Violence Prevention Events }}$}


Proportions of topics covered as part of most recently attended violence prevention event can be found in the right-hand column of Table 3. The three most commonly reported topics mentioned during events reasons included: "abuse in relationships" (73\%), "sexual assault" (71\%) and "gender roles" (64\%). "Relationships" (61\%) and "power" (61\%) were also among the more commonly reported topics. The three least commonly endorsed topics included: "veterans and people in the military" (5\%), being accused of harassment or violence (8\%), and "substance abuse" (14\%). On average, respondents reported that nearly seven different topics $(M$ $=6.87 ; S D=3.73$ ) were discussed at their most recently attended violence prevention event. On average, respondents reported that nearly four different methods $(M=3.69 ; S D=1.75)$ were used to deliver content at their most recently attended violence prevention event.

\section{$\underline{\text { Perceptions of Violence Prevention Event Content Classes }}$}

Fit indices for the two, three, four, and five class LCA models are provided in Table 2. We selected the 4-class model as the best solution, because it had substantially smaller BIC and AIC values than the three-class solution, greater entropy than the three-class solution, very high classification probabilities, and conceptually clear group characteristics. Though the LMR test for the four-class was non-significant, the BLR was significant and recent research has suggested it is more accurate than the LRT for determining the true number of classes (Nylund, Asparouhov, \& Muthén, 2007). Though the five-class solution has lower BIC and AIC values in addition to a significant BLR, it was rejected due to its lower entropy and overall classification probabilities.

Table 2 about here 
The probability of endorsement for each topic by content class is displayed in Table 3 , below. As suggested by the numbers presented in Table 3, class size varied considerably, and each displayed a distinct pattern of indicator endorsement. As the purpose of LCA is to identify patterns of item endorsement which distinguish classes from one another, variable by variable difference testing is not typically done for LCA indicators. In other words, classes are derived from the overall pattern of responses across all indicators simultaneously. Below, we describe each of the four content classes groups in more detail.

Table 3 about here

The first group consisted of 30 men $(9.4 \%)$ who reported attending events with an emphasis on the topic of violence. Specifically, participants who attended the events of this type were most likely to report "abuse in relationships," "child abuse," and "sexual assault" as being discussed during their most recently attended event. Given the overall emphasis on topics explicitly related to violence, we named this class of content coverage, "Awareness." Only about $1 / 3$ of men in this group reported attending events in which the topics of gender roles (33\%) and power $(36 \%)$ were discussed.

The second group consisted of 148 men (46.4\%) who reported attending events in which "gender roles," "power," "abuse in relationships," and "relationships" were the most commonly discussed topics during their most recently attended event. Gender and power were the most prevalent topics in events attended by this group, showing up in $83 \%$ and $79 \%$ of programs, respectively. Given that the endorsement pattern emphasized violence, power, and gender roles, this group was named, "Awareness + Gender \& Power." Almost a third of men in this group 
(74\%) also reported that the topic of sexual assault was covered during their most recently attended event.

The third group was termed "Awareness + Gender \& Power + Action," because of the coverage of topics listed in the previous two groups combined with an emphasis on skill-building and action-related topics. This group consisted of 64 men (20.1\%) who reported attending events in which "relationships," "abuse in relationships," "power," and "sexual assault" were endorsed by over $90 \%$ of men in this group, and issues such as "jealousy and control," and "gender roles" were endorsed by at least $80 \%$ of men in this group. Distinguishing this group, however, was its attention to action; 64\% reported hearing about "how to help someone who has been abused," $67 \%$ about "how to get other people involved in ending violence," and $84 \%$ about "being a positive bystander."

The fourth and final group consisted of 77 men $(21.4 \%)$ who reported attending events with the lowest level of endorsement of nearly all content indicators; accordingly, we termed this class of violence prevention events "Undifferentiated." As shown in Table 3, men attending this class of event had a less than 50\% chance of reporting any of the topics assessed in this study as being covered during their most recently attended event.

\section{$\underline{\text { Factors Influencing Men's Perceptions of Violence Prevention Programming Content }}$}

Results of chi-square tests (using a Bonferroni correction for multiple comparisons) revealed the following factors influenced men's perceptions of violence prevention programming content: methods of content delivery, involvement in organizing, motivation, and confidence. Specifically, significantly more content delivery methods were used at "Awareness + Gender \& Power + Action" events than any other event. Additionally, while "Awareness + Gender \& Power + Action" events had the highest percentage of study participants involved as organizers 
(63\%), it was only significantly higher than the percentages at two other events ("Undifferentiated" and "Awareness"). There was no difference in the proportion of study participants involved as organizers who attended "Awareness + Gender \& Power" (51\%) compared to "Awareness + Gender \& Power + Action" events. Furthermore, participants who attended "Undifferentiated" events rated their motivation for anti-violence work as significantly lower than those who attended "Awareness + Gender \& Power" and "Awareness + Gender \& Power + Action", but not "Awareness" events. There were no significant differences in motivation between men who attended "Awareness", "Awareness + Gender \& Power", and “Awareness + Gender \& Power + Action” events. Finally, participants who attended "Undifferentiated" events rated their confidence for engaging in anti-violence work as significantly lower (5.04) than those who attended all other types of events. Men who attended either "Awareness" or "Awareness + Gender \& Power" events rated their confidence for engaging in anti-violence work significantly higher than those who attended "Awareness + Gender \& Power + Action" events. There were no significant differences in confidence between men who attended "Awareness" and "Awareness + Gender \& Power" events.

The chi-square test regarding prediction of event region as a function of content class was not significant. Thus, the region where men attended their violence prevention event was not associated with differences in perceptions programming content. Results of all pairwise comparisons for distal outcomes are displayed in Table 4, below.

Table 4 about here 


\section{DISCUSSION}

Given scarce information regarding the range of topics and content included under the banner of "violence against women" prevention globally, our first aim was to assess what content is included in GBV prevention events around the world. The two most commonly reported topics by men in our sample were "abuse in relationships" and "sexual assault." Given the strong emphasis on the role gender norms plays in perpetuating violence against women and girls in prevention frameworks (World Health Organization, 2007; Gupta, 2000) it is also noteworthy that the topic of "gender roles" was reported a strong majority of the time but, not consistently across event types. Encouragingly, event types that included gender also tended to include attention to power. This is important because previous research stresses the importance of including gender focused content to achieve prevention outcomes related to health issues profoundly impacted by gender and social norms, such as gender-based violence and HIV infection (Dworkin et al., 2013). Indeed, evidence documenting the effectiveness of gender transformative approaches on men's violence-related attitudes and behaviors is growing (Casey, Carlson, Two-Bulls, \& Yager, 2016; Dworkin, Treves-Kagan, \& Lippman, 2013; Jewkes, Flood, \& Lang, 2015). Gender transformative approaches "seek to transform gender relations through critical reflection and the questioning of individual attitudes, institutional practices and broader social norms that create and reinforce gender inequalities and vulnerabilities" (UNFPA \& Promundo, 2010, p. 14). The twin findings that types of events did not differ between North America and other regions and that a majority of events are incorporating this dual focus on gender and power is heartening, and implies that a majority of prevention event attendees around the world are gaining exposure to potentially effective programming. At the same time, a substantial minority of men in our sample (i.e., the men in the "Awareness" and 
"Undifferentiated groups") attended events in which gender was not perceived to be a focus. Future studies may wish to analyze the specific messaging of prevention programming directly to clearly distinguish the absence of gender focused content from poor content delivery. It may be, for example, that some of the events in the latter two groups were intended to be initial, inviting, awareness-building programs in which introducing issues of gender and power may have seemed premature.

Regarding the second aim to identify distinct combinations among GBV prevention programming content in events, findings revealed salient distinctions. A LCA revealed four conceptually meaningful topic content clusters at events attended by men in our sample:

"Awareness," "Awareness + Gender \& Power," "Awareness + Gender \& Power + Action," and "Undifferentiated." On a basic level, this highlights the heterogeneity among events with an ostensible focus on GBV prevention around the world, and suggests that even if men report taking part in a violence prevention event, it cannot be assumed they have been exposed to similar content.

Most notably, men who attended events in the "Awareness + Gender \& Power + Action" cluster received programming which combined gender related content with strategies on how to address the problem of GBV (e.g., How to help someone who has been abused, or other people involved in ending violence; being a positive bystander). This was the second smallest class, and yet the only class in which an overwhelming majority of men reported attending an event where topics included strategies for men to take an active role in addressing GBV. While incorporating skill-building into prevention programming is time-consuming and perhaps beyond the intended scope of many events, actual behavioral change requires participants to see and practice the “new” targeted skills (Ajzen, 1991). Indeed, several existing, comprehensive prevention 
programs, with documented evidence of impacting men's behavior in violence preventative ways, incorporate opportunities for building self-efficacy for new skills. For example, programs such as Stepping Stones (Jewkes, et al., 2014) and the Men and Women in Partnership Initiative (Hossain, et al., 2014) have demonstrated positive impacts on GBV-related attitudes and behaviors among African men using curricula incorporating communication, relationship, and sexual-safety skill building. Additionally, these are programs that engage men in comprehensive curriculum that unfolds over time, in the context of mutually supportive men's discussion groups. As men's engagement programs proliferate globally, it will be important to maximize the extent to which men have an opportunity to not only be exposed to ideas about violence and gender, but to "try on" skills for promoting peaceful, respectful relationships in their families, social networks and communities. It will also be important to assess the "dosage" needed to prompt skill development, and whether shorter programs such as a proportion of the events captured here, can accomplish this. Overall, we echo Fishbein et al. (2001) who suggest that efforts must focus on developing self-efficacy for prevention behaviors, and associating prevention behavior with positive emotions.

Our third aim was to assess whether certain content prerception profiles were more common in some regions of the world, organized differently, and had unique impacts on men's own violence prevention-related intentions. Chi-square analyses examining factors influencing men's perceptions of violence prevention programming content showed that only regionality did not have overall significant associations with type of event. The remaining associations suggest that events with different content groupings are different in other important ways that can inform the way organizations shape violence prevention events. Some of these associations are readily decipherable. Not surprisingly, the "Awareness + Gender \& Power + Action" events used 
significantly more content delivery methods. In addition, findings demonstrate that content groups with the highest proportion of organizers were "Awareness + Gender \& Power + Action" and "Awareness + Gender \& Power" events.

Less easily discernable are the study's findings related to men's confidence and motivation associated with the content groups. Men's motivation for prevention work appears to be stoked by events with clear messages about "relationship abuse" and "sexual assault" but not from the added focus on "gender" or "action." Several factors may be at play here. The two types of events - "Awareness + Gender \& Power + Action" and "Awareness + Gender \& Power" - that should, theoretically, spark the most motivation and confidence also had higher proportions of organizers, who themselves, probably weren't greatly impacted by the content of the event, given that they created it, at least in part. In addition, perhaps the reality that a majority of the events were one-time events (blinded for review) meant that the event was not enough to boost motivation beyond what men come to the events with already. Lastly, the men in this sample were already willing to attend a violence prevention programming event, and previous analysis revealed that overall already had very high levels of gender equitable attitudes among men (blinded for review). Taken together, the types or classes of events did not clearly inform pathways of motivation.

Men's confidence for prevention work benefits from having perceived a clear message about "relationship abuse," "sexual assault," and the role of "gender" but dips down when the "action" aspect is added in. This may be a distinction between attitudes and behaviors. Men's confidence about engaging in prevention work may increase because attending an event that has clear anti-violence messages and talks about the role of gender expands their understanding of the problem. However, greater understanding doesn't require any additional action from men. It 
could be that, when confronted with the perceived expectation that men use the skills they've learned at an event to prevent violence, their confidence goes down. This could be because these skills are new and they haven't really practiced them and/or masculine gender norms strongly discourage men from confronting other men about their use of violence (Berkowitz, 2004). It could also be that events did not engage participants in skill-building, but may have exposed them to the ideas of being a prosocial bystander; the existence and level of skill-building at the events was not assessed in this study.

As global efforts to engage male-identified individuals in ending GBV increase and develop in sophistication, it is increasingly relevant to understand what motivates and builds confidence in their participation. In our survey design, motivation and confidence were different constructs; the different relationship between content and confidence compared to content and motivation is important to be aware of as we consider developing men's activism capabilities in program development because of the need to capture these unique attitude and potential behavioral processes. Increasing men's confidence is valuable to the purpose of ending GBV if paired with motivation to act (Berkowitz, 2004). Future research could examine the motivational impact of varying levels of content delivery methods and involvement in organizing events (Crooks, Goodall, Hughes, Jaffe, \& Baker, 2007; Fabiano, Perkins, Berkowitz, Linkenbach \& Stark, 2003). Additionally, investigation into how the mechanism of action-oriented content impacts men's confidence in prevention efforts is warranted.

The finding that men's motivation may be related to their role as organizers of events has specific implications for organizational and community practice. Programmatic efforts aimed at motivating men's participation in GBV prevention could analyze and evolve their organizational approach to invite more individual men to become involved as organizers in the efforts, and 
increase the organization's use of community mobilization. Organizational approaches that do both, such as Sonke's Community Action Team approach (Community Action Teams, 2016), are growing in use across the globe. Another example is SASA! from Raising Voices (SASA!, 2016), in Uganda. SASA! illustrates a community mobilization approach that was found effective in changing GBV related attitudes and behaviors of men in a randomized controlled trial (Abramsky, et al., 2014). These types of programmatic efforts invite individual men to be "activists" and leaders with a community mobilization approach. Further research could provide a fuller understanding of both the meaning of "being an organizer" for male-identified participants, and what particular programmatic or conceptual approaches of engaging men as organizers show the greatest level of motivation.

The study described above has the following limitations. First, despite recruitment strategies to reach participants worldwide, more than half of the study's participants were from North America. Second, the trilingual (English, French, Spanish) online survey limited the recruitment to individuals who read the survey languages and had reliable Internet and computer access. In part, this may explain the low response rate from some geographic regions. Additionally, despite careful survey testing, some survey language (such as "power") may have different connotations across specific contexts. Third, the survey consisted of self-report measures that do not account for social desirability bias and/or (in)accuracy of self-report. Fourth, over a third of the sample was comprised of men who self-identified as is "helping to end violence against women" for 6+ years; we do not know how results would vary with a less (or more) experienced sample of men. Other data that may account for differences in perceptions (such as number of events attended) is not available in this project. Fifth, our data reflect men's perceptions of event content rather than a content analysis of attended prevention events. Finally, 
our data do not permit us to assess the representativeness of the events reported on by participants in this sample.

While theoretical frameworks such as a profeminist approach or gender transformative approach can help shape the content and strategies of events aimed at engaging male-identified individuals in ending GBV, more research is needed about mechanics of prevention events' success at increasing confidence and motivation to take an active anti-violence role. Specifically, more research is needed to understand how events shape male-identified individuals' confidence and motivation to address GBV through prevention. The ultimate goal is to end GBV; increasing the efficacy in mobilizing and sustaining accountable male involvement, commitment, and leadership to reach that goal is one important pieces of the movement to realize gender equity. 


\section{$\underline{\text { Footnotes }}$}

1. In this paper we use the term "GBV prevention event" refer to any occasion when participants were present where information related to GBV prevention was being actively presented. We intentionally use the word "event" rather than "program" because we did not collect data to determine if the occasion was part of series of events or specified curriculum. 


\section{REFERENCES}

Abramsky, T., Devries, K., Kiss, L., Nakuti, J., Kyegombe, N., Starman, E., . . Watts, C. (2014). Findings from the SASA! Study: a cluster randomized controlled trial to assess the impact of a community mobilization intervention to prevent violence against women and reduce HIV risk in Kampala, Uganda. BMC Medicine, 12, 122. doi:10.1186/s12916-014-0122-5

Ajzen, I. (1991). The theory of planned behavior. Organizational Behavior and Human Decision Processes, 50, 179-211. doi:10.1016/0749-5978(91)90020-T

Akaike, H. (1987). Factor analysis and AIC. Psychometrika, 52, 317-332.

Asparouhov, T., \& Muthén, B. (2014, October 7). Variable-specific entropy contribution. Retrieved from Statmodel.com: https://www.statmodel.com/download/UnivariateEntropy.pdf

Banyard, V. L., Plante, E. G., \& Moynihan, M. M. (2004). Bystander education: Bringing a broader community perspective to sexual violence prevention. Journal of Community Psychology, 1, 61-79. doi: 10.1002/jcop.10078

Berkowitz, A. (2004, October). Working with men to prevent violence against women: An Overview (Part One). Retrieved from VAWnet, a project of the National Resource Center on Domestic Violence/Pennsylvania Coalition Against Domestic Violence: http://www.vawnet.org/applied-research-papers/print-document.php?doc_id=413

Black, M., Basile, K., Breiding, M. J., Smith, S., Walters, M., Merrick, M. T., . . Stevens, M. (2011). The National Intimate Partner and Sexual Violence Survey (NISVS): 2010 Summary Report. Atlanta, GA: National Center for Injury Prevention and Control, Centers for Disease Control and Prevention. 
Black, M., Basile, K., Breiding, M., Smith, S., Walters, M., Merrick, M., . . Stevens, M. (2011). The National Intimate Partner and Sexual Violence Survey (NISVS): 2010 Summary Report. National Center for Injury Prevention and Control. Atlanta, GA: Centers for Disease Control and Prevention.

Brown, A., \& Messman-Moore, T. (2010). Personal and perceived peer attitudes supporting sexual aggression as predictors of male college students' willingness to intervene against sexual aggression. Journal of Interpersonal Violence, 25, 503-517. doi:10.1177/0886260509334400

Carlson, J., Casey, E., Edleson, J., Tolman, R., Walsh, T., \& Kimball, E. (2015). Strategies to engage men and boys in violence prevention: A global organizational perspective. Violence Against Women, 21, 1406-1425. doi:10.1177/1077801215594888

Casey, E., \& Ohler, K. (2012). Being a positive bystander: Male antiviolence allies' experiences of "stepping up". Journal of Interpersonal Violence, 27(1). doi:10.1177/0886260511416479

Casey, E., \& Smith, T. (2010). “'How can I not?’: Men’s pathways to involvement in anti violence against women work. Violence Against Women, 16(8), 953-973. doi:10.1177/1077801210376749

Casey, E., Carlson, J., Two-Bulls, S., \& Yager, A. (2016). Gender transformative approaches to engaging men in gender-based violence prevention: A review and conceptual model. Trauma, Violence \& Abuse. doi:10.1177/1524838016650191

Coker, A. L., Cook-Craig, P. G., Williams, C. M., Fisher, B. S., Clear, E. R., Garcia, L. S., \& Hegge, L. M. (2011). Evaluation of green dot: An active bystander intervention to reduce sexual violence on college campuses. Violence Against Women, 17, 777-796. 
doi: $10.1177 / 1077801211410264$

Community Action Teams. (2016). Retrieved from Sonke Gender Justice:

www.genderjustice.org.za/community-education-mobilisation/community-action-teams/

Crooks, C., Goodall, G., Hughes, R., Jaffe, P., \& Baker, L. (2007). Engaging men and boys in preventing violence against women: Appyling a coginitive-behavioral model. Violence Against Women, 13, 217-239. doi:10.1177/1077801206297336

Dworkin, S., Grabe, S., Lu, T., Hatcher, A., Kwena, Z., Bukusi, E., \& Mwaura-Muira, E. (2013). Property rights violations as a structural driver of women's HIV risks in Nyanza and Western Provinces, Kenya. Archives of Sexual Behavior, 42, 703-715. doi:10.1007/s10508-012-0024-6

Dworkin, S., Treves-Kagan, S., \& Lippman, S. (2013). Gender-transformtive interventions to reduce HIV risks and violence with heterosexually-active men: A review of the global evidence. AIDS and Behavior, 17, 2845-2863. doi:10.1007/s10461-013-0565-2

Fabiano, P., Perkins, H. W., Berkowitz, A. B., Linkenbach, J., \& Stark, C. (2004). Engaging men as social justice allies in ending violence against women: Evidence for a social norms approach. Journal of American College Health, 52, 105-112.

doi: $10.1080 / 07448480309595732$

Fishbein, M., Triandis, H. C., Kanfer, F. H., Becker, M., Middlestadt, S. E., \& Eichler, A. (2001). Factors influencing behavior and behavior change. In A. Baum, \& T. A. Revenson, Handbook of health psychology. Mahwah, NJ: Lawrence Erlbaum Associates. Flood, M. (2005). Changing men: Best practice in sexual violence education. Women Against Violence, 18, 26-36.

Foshee, V., K.E., B., Ennett, S., Linder, G., Benefield, T., \& Suchindran, C. (2004). Assessing 
the long-term effects of the Safe Dates program and a booster in preventing and reducing adolescent dating violence victimization and perpetration. American Journal of Public Health, 94, 619-624.

Gupta, G. (2000). Gender, sexuality, and HIV/AIDS: The what, the why, and the how. Canadian HIV/AIDS Policy \& Law review, 5(4), 86-93.

Hossain, M., Zimmerman, C., Kiss, L., Abramsky, T., Kone, D., Bakayoko-Topolska, M., .. . Watts, C. (2014). Working with men to prevent intimate partner violence in a conflict affected setting: a pilot cluster randomized controlled trial in rural Côte d'Ivoire. BMC Public Health, 14, 1-28. doi:10.1186/1471-2458-14-339

IBM Corp. (2015). IBM SPSS Statistics for Windows, Version 23.0. Armonk, NY: IBM Corp.

Jewkes, R., Flood, M., \& Lang, J. (2015). From work with men and boys to changes of social norms and reductions of inequities in gender relations: A conceptual shift in preventions of violence against women and girls. Lancet, 385(9977), 1580-1589.

doi:10.1016/S0140-6736(14)61683-4

Jewkes, R., Gibbs, A., N., J.-S., Willan, S., Misselhorn, A., Mushinga, M., . . Skiweyiya. (2014). Stepping Stones and Creating Futures intervention: shortened interrupted time series evaluation of a behavioural and structural health promotion and violence prevention intervention for young people in informal settlements in Durban, South Africa. BMC Public Health, 14, 1-14. doi:10.1186/1471-2458-14-1325

Katz, J., \& Moore, J. (2013). Bystander education training for campus sexual assault prevention: an initial meta-analysis. Violence and Victims, 28(6), 1054-1067.

Kilmartin, C. T., Smith, T., Green, A., Heinzen, H., Kuchler, M., \& Kolar, D. (2008). A real time social norms intervention to reduce college men’s sexism. Sex Roles, 59, 264-273. 
Kimball, E., Edleson, J. L., Tolman, R. M., Neugut, T. B., \& Carlson, J. (2013). Global efforts to engage men in preventing violence against women: An international survey. Violence Against Women, 924-939. doi:10.1177/1077801213498391

Lanza, S. T., Tan, X., \& Bray, B. C. (2013). Latent class analysis with distal outcomes: A flexible model-based approach. Structural Equation Modeling, 20, 1-26. doi:10.1080/10705511.2013.743377

Lanza, S., \& Collins, L. (2008). A new SAS procedure for latent transition analysis: transitions in dating and sexual risk behavior. Developmental Psychology, 44(2). doi:10.1037/0012-1649.44.2.446

Lo, Y., Mendell, N., \& Rubin, D. (2001). Testing the number of component in a normal mixture. Biometrika, 88, 767-778.

McLachlan, G., \& Peel, D. (2000). Finite mixture models. New York: Wiley.

McMahon, S. (2015). Call for research on bystander intervention to prevent sexual violence: The role of campus environments. American Journal of Community Psychology, 55, 472-489. doi:10.1007/s10464-015-9724-0

McMahon, S., Peterson, N., Winter, S., Palmer, J., Postmus, J., \& Koenick, R. (2015). Predicting Bystander Behavior to Prevent Sexual Assault on College Campuses: The Role of Self Efficacy and Intent. American Journal of Community Psychology, 56(1-2), 46-56. doi:10.1007/s10464-015-9740-0

Moore, T., \& Stuart, G. (2005). A review of the literature on masculinity and partner violence. Psychology of Men \& Masculinity, 6(1), 46-61. doi:10.1037/1524-9220.6.1.46

Murnen, S. K., Wright, C., \& Kaluzny, G. (2002). If "boys will be boys," then girls will be victims? A meta-analytic review of the research that relates masculine ideology to sexual 
aggression. Sex Roles, 46(11), 359-375.

Muthén, L. K., \& Muthén, B. O. (1998-2015). Mplus User's Guide. Seventh Edition. Los Angeles, California: Muthén \& Muthén.

Nation, M., Crusto, C., Wandersman, A., Kumpfer, K., Seybolt, D., Morrissey-Kane, E., \& Davino, K. (2003). What works in prevention: Principles of effective prevention programs. American Psychologist, 58(6/7), 449-456. doi:10.1037/0003-066X.58.6-7.449

Nylund, K., Asparouhov, T., \& Muthén, B. O. (2007). Deciding on the number of classes in latent class analysis and growth mixture modeling: A Monte Carlo simulation study. Structural Equation Modeling, 14(4), 535-569.

Peacock, D., \& Barker, G. (2014). Working with men and boys to prevent gender-based violence: Principles, lessons, and ways forward. Men and Masculinities, 17(5), 578-599. doi:10.1177/1097184X14558240

Ramaswamy, V., Desarbo, W., Reibstein, D., \& Robinson, W. (1993). An empirical pooling approach for estimating marketing mix elasticities with PIMS data. Marketing Science, 12(1), 103-124.

SASA! (2016). Retrieved from Raising Voices: http://raisingvoices.org/sasa/

Schwartz, G. (1978). Estimating the dimension of a model. The Annals of Statistics, 6, 461-464.

Storer, H., Casey, E., Carlson, J., Edelson, J., \& Tolman, R. (2016). Primary prevention is? A global perspective on how orgnaization engaging men in preventing gender-based violence conceptualize and operationalize thier work. Violence Against Women, 22(2), 249-268. doi:10.1177/1077801215601247

Taylor, B., Stein, N., Mumford, E., \& Woods, D. (2013). Shifting Boundaries: an experimental evaluation of a dating violence prevention program in middle schools. Prevention 
Science, 14(1), 64-76. doi:10.1007/s11121-012-0293-2.

U.N. Women. (2015). HeForShe. Retrieved from http://www.heforshe/org/

UNFPA, \& Promundo. (2010). Engaging men and boys in gender equality and health. Retrieved from www.unfpa.org. Women, U. N. (2014). Annual Report. Retrieved from http://www2.unwomen.org/ /media/headquarters/attachments/sections/library/publicatio ns/2015/untf-annualreport-2014-en.pdf?v=1\&d=20150723T143649

World Health Organization. (2007). Engaging men and boys in changing gender-based inequity in health: Evidence from programme interventions. Geneva: World Health Organization.

World Health Organization, \& London School of Hygiene and Tropical Medicine. (2010). Preventing intimate partner and sexual violence against women: taking action and generating evidence. Geneva: World Health Organization. 
Table 1

Sample Characteristics

\begin{tabular}{|c|c|c|c|}
\hline & & $\underline{\mathrm{N}}$ & $\underline{\%}$ \\
\hline \multicolumn{4}{|l|}{ Age } \\
\hline & $18-21$ & 14 & 4.4 \\
\hline & $22-25$ & 26 & 8.2 \\
\hline & $26-30$ & 58 & 18.2 \\
\hline & $31-40$ & 83 & 26.0 \\
\hline & $41-50$ & 44 & 13.8 \\
\hline & $51-60$ & 56 & 17.6 \\
\hline & 61 or over & 38 & 11.9 \\
\hline \multicolumn{4}{|l|}{ Region } \\
\hline & Africa & 15 & 4.7 \\
\hline & Asia & 10 & 3.1 \\
\hline & Australia \& & & \\
\hline & New Zealand & 4 & 1.3 \\
\hline & Europe & 31 & 9.7 \\
\hline & Latin America \& & & \\
\hline & the Caribbean & 43 & 13.5 \\
\hline & North America & 178 & 55.8 \\
\hline & Missing & 38 & 11.9 \\
\hline \multicolumn{4}{|l|}{ Primary Written Language } \\
\hline & English & 218 & 68.3 \\
\hline & French & 6 & 1.9 \\
\hline & Spanish & 61 & 19.1 \\
\hline & Other & 31 & 9.8 \\
\hline & Missing & 3 & .9 \\
\hline \multicolumn{4}{|l|}{ Primary Spoken Language } \\
\hline & English & 208 & 65.2 \\
\hline & French & 6 & 1.9 \\
\hline & Spanish & 60 & 18.8 \\
\hline & Other & 41 & 12.8 \\
\hline & Missing & 4 & 1.3 \\
\hline Volunteer for Organization & Yes & 173 & 54.2 \\
\hline that Includes Violence & No & 140 & 43.9 \\
\hline $\begin{array}{l}\text { Prevention as Part of its } \\
\text { Mission? }\end{array}$ & Missing & 6 & 1.9 \\
\hline
\end{tabular}




\begin{tabular}{|c|c|c|c|}
\hline Works at an Organization that & Yes & 94 & 29.5 \\
\hline Provides Treatment for & No & 126 & 70.5 \\
\hline Violent Men? & Missing & 0 & 0 \\
\hline $\begin{array}{l}\text { Number of Years Spent } \\
\text { Helping to End Violence } \\
\text { Against Women }\end{array}$ & $\begin{array}{l}0-5 \\
6-10 \\
11-15 \\
16-20 \\
\text { More than } 20 \\
\text { Missing }\end{array}$ & $\begin{array}{l}150 \\
74 \\
28 \\
12 \\
1 \\
54\end{array}$ & $\begin{array}{c}47.0 \\
23.2 \\
8.8 \\
3.8 \\
0.3 \\
16.9\end{array}$ \\
\hline $\begin{array}{l}\text { Hours Per Week Spent } \\
\text { Working to End Violence } \\
\text { Against Women }\end{array}$ & $\begin{array}{l}0-5 \\
6-10 \\
11-15 \\
16-20 \\
\text { More than } 20 \\
\text { Missing }\end{array}$ & $\begin{array}{c}142 \\
43 \\
29 \\
4 \\
89 \\
12\end{array}$ & $\begin{array}{c}44.5 \\
13.5 \\
9.1 \\
1.3 \\
27.9 \\
3.8\end{array}$ \\
\hline $\begin{array}{l}\text { Year in Which Most Recent } \\
\text { Violence Prevention Event } \\
\text { Was Attended }\end{array}$ & $\begin{array}{l}2011 \\
2012 \\
2013 \\
2014 \\
\text { Missing }\end{array}$ & $\begin{array}{c}4 \\
13 \\
198 \\
89 \\
15 \\
\end{array}$ & $\begin{array}{c}1.3 \\
4.1 \\
62.1 \\
27.9 \\
4.7 \\
\end{array}$ \\
\hline
\end{tabular}


Table 2. Latent class analysis: Fit indicators for models of different class sizes

\begin{tabular}{llllllll}
\hline & & & & & & \\
Model & BIC $_{\text {ssa }}$ & AIC & Entropy & Class Sizes & Quality & LMR & BLR \\
\hline 2-class & 6081 & 6059 & .85 & 220,99 & $.96, .93$ & $* *$ & $* *$ \\
3-class & 5970 & 5936 & .81 & $72,132,115$ & $.96, .87, .92$ & $*$ & $* *$ \\
4-class & 5910 & 5865 & .85 & $77,30,64,148$ & $.91, .94, .95, .92$ & NS & $* *$ \\
5-class & 5883 & 5827 & .83 & $71,106,63,51,28$ & $.93, .88, .96, .78, .91$ & NS & $* *$ \\
\hline
\end{tabular}

$* \mathrm{p}<.05, * * \mathrm{p}<.001$ 
Table 3. Method of Content Delivery Endorsement by Class

\begin{tabular}{|c|c|c|c|c|c|}
\hline Method & $\begin{array}{c}\text { Class } 1 \\
\text { Aware } \\
\text { ness } \\
(\mathbf{n}=\mathbf{3 0})\end{array}$ & $\begin{array}{c}\text { Class } 2 \\
\text { Awareness }+ \\
\text { Gender \& Power } \\
(\mathbf{n}=\mathbf{1 4 8})\end{array}$ & $\begin{array}{c}\text { Class } 3 \\
\text { Awareness + } \\
\text { Gender \& Power } \\
+ \text { Action } \\
(n=64) \\
\end{array}$ & $\begin{array}{c}\text { Class } 4 \\
\text { Undifferentiated } \\
\qquad(\mathbf{n}=77)\end{array}$ & $\begin{array}{c}\text { Full } \\
\text { sample }\end{array}$ \\
\hline Someone gave a presentation or speech & $80 \%$ & $76 \%$ & $91 \%$ & $62 \%$ & $76 \%$ \\
\hline Someone led a discussion & $43 \%$ & $74 \%$ & $73 \%$ & $47 \%$ & $64 \%$ \\
\hline $\begin{array}{l}\text { People who have been affected by violence shared } \\
\text { their stories }\end{array}$ & $60 \%$ & $30 \%$ & $53 \%$ & $20 \%$ & $35 \%$ \\
\hline $\begin{array}{l}\text { People participated in a community activity, like a } \\
\text { march }\end{array}$ & $20 \%$ & $13 \%$ & $23 \%$ & $20 \%$ & $17 \%$ \\
\hline $\begin{array}{l}\text { Sports stars, leaders, or celebrities spoke about the } \\
\text { issue of violence }\end{array}$ & $7 \%$ & $10 \%$ & $22 \%$ & $7 \%$ & $11 \%$ \\
\hline $\begin{array}{l}\text { We volunteered to help people who have been } \\
\text { abused (e.g. cooked a meal at a shelter, helped with } \\
\text { childcare, etc.) }\end{array}$ & $17 \%$ & $0 \%$ & $5 \%$ & $3 \%$ & $3 \%$ \\
\hline $\begin{array}{l}\text { People could take a pledge to take a stand against } \\
\text { violence }\end{array}$ & $17 \%$ & $31 \%$ & $42 \%$ & $20 \%$ & $29 \%$ \\
\hline
\end{tabular}


There were interactive activities I could participate in 
Table 4. Chi-square Difference test Results by Content Classes

\begin{tabular}{|c|c|c|c|c|c|c|c|c|c|c|c|}
\hline \multirow[b]{2}{*}{ Variable } & \multirow[t]{2}{*}{$\chi^{2}$} & \multirow[t]{2}{*}{ DF } & \multirow[t]{2}{*}{$p$} & \multicolumn{2}{|c|}{$\begin{array}{c}\text { Class 1 } \\
\text { Awareness } \\
(N=30)\end{array}$} & \multicolumn{2}{|c|}{$\begin{array}{c}\text { Class 2 } \\
\text { Awareness + } \\
\text { Gender \& } \\
\text { Power } \\
(N=148)\end{array}$} & \multicolumn{2}{|c|}{$\begin{array}{c}\text { Class 3 } \\
\text { Awareness + } \\
\text { Gender \& } \\
\text { Power + } \\
\text { Action } \\
(N=64)\end{array}$} & \multicolumn{2}{|c|}{$\begin{array}{c}\text { Class } 4 \\
\text { Undifferentiated } \\
(N=77)\end{array}$} \\
\hline & & & & $\mathrm{M}$ & $\mathrm{SE}$ & $\mathrm{M}$ & SE & $\mathrm{M}$ & $\mathrm{SE}$ & $\mathrm{M}$ & $\mathrm{SE}$ \\
\hline $\begin{array}{l}\text { North American } \\
\text { Event }\end{array}$ & 4.10 & 3 & .25 & .69 & .11 & .61 & .05 & .73 & .06 & .57 & .07 \\
\hline $\begin{array}{l}\text { \# of Content } \\
\text { Delivery Methods }\end{array}$ & 70.03 & 3 & $<.001$ & $3.75_{\mathrm{a}}$ & .33 & $3.63 \mathrm{a}$ & .15 & $5.04_{b}$ & .22 & $2.71_{c}$ & .18 \\
\hline $\begin{array}{l}\text { Involvement in } \\
\text { Organizing }\end{array}$ & 11.89 & 3 & $<.05$ & $.43_{\mathrm{ab}}$ & .10 & $.51_{\mathrm{a}}$ & .045 & $.63 \mathrm{a}$ & .06 & $.34_{\mathrm{ab}}$ & .06 \\
\hline Motivation & 13.87 & 3 & $<.05$ & $5.76_{a b}$ & .26 & $6.28 \mathrm{a}$ & .14 & $5.94 \mathrm{a}$ & .12 & $5.42_{\mathrm{ab}}$ & .20 \\
\hline Confidence & 21.73 & 3 & $<.001$ & $5.83_{\mathrm{ac}}$ & .25 & $6.20_{\mathrm{ac}}$ & .15 & $5.68 \mathrm{a}$ & .13 & $5.04_{b}$ & .21 \\
\hline
\end{tabular}

Note: Means with differing subscripts within rows are significantly different at $\mathrm{p}<.05$ 
Christopher T. Allen, Ph.D. is an Assistant Professor of Psychology at the University of Massachusetts Lowell. He earned his doctorate in Clinical-Community Psychology at the University of South Carolina. His research is primarily focused on how gender socialization of men and boys has contributed to their underrepresentation in efforts to prevent gender-based violence.

Juliana Carlson, $\mathrm{AM}, \mathrm{PhD}$, is an assistant professor at the University of Kansas School of Social Welfare. She received her doctorate from the University of Minnesota, School of Social Work. Her research interests include gender-based violence prevention, intersectional theory, and social welfare policy.

Erin Casey, Ph.D. is an Associate Professor of Social Work at the University of Washington, Tacoma and Co-Director of the Mobilizing Men for Violence Prevention Research Collaboration. Her research focuses on examining ecological and community-engaged approaches to violence prevention, including engaging men proactively as anti-violence allies, mobilizing change agents within communities, and exploring intersections between violence, masculinities, and sexual risk.

Richard M. Tolman, Ph.D. is the Sheldon D. Rose Collegiate Professor of Social Work at the University of Michigan and Co-Director of the Mobilizing Men for Violence Prevention Research Collaboration. His research focuses on preventing intimate partner violence. His current projects include work on engaging expectant and new fathers to prevent abuse and promote positive partnering and parenting, digital dating abuse, and engaging men as antiviolence allies. 
Cliff Leek, Ph.D. is an Assistant Professor of Sociology at the University of Northern Colorado and current President of the American Men's Studies Association, Managing Editor of the journal Men and Masculinities, and a Research Fellow with Men Advocating Real Change. He has served as Program Director of the Center for the Study of Men and Masculinities and his research examines ways in which individuals and groups in positions of privilege engage in social justice activism. 